\title{
Progressive Increase Trend in HPV-Related Oropharyngeal Squamous Cell Carcinoma in Brazil
}

\author{
Rafael Cardoso Pires ${ }^{10}$ Raiany Carvalho ${ }^{20}$ Ricardo Ribeiro Gama ${ }^{10}$ André Lopes Carvalho ${ }^{3(0)}$ \\ Carlos Roberto Santos ${ }^{1}$ (i) Renato de Castro Capuzzo ${ }^{10}$ \\ ${ }^{1}$ Head and Neck Surgery Department, Hospital de Câncer de Barretos, \\ Barretos, SP, Brazil \\ 2 Researcher Support Center, Hospital de Câncer de Barretos, \\ Address for correspondence Rafael Cardoso Pires, MD, Head and \\ Barretos, SP, Brazil \\ Neck Surgery Department, Barretos Cancer Hospital, Barretos, SP, \\ 3 Post-Graduation Program, Hospital de Câncer de Barretos, Barretos, \\ SP, Brazil \\ Int Arch Otorhinolaryngol 2022;26(1):e132-e136.
}

\begin{abstract}
Keywords

- oropharyngeal cancer

- Human Papillomavirus

- prevalence

- temporal trend

Introduction The prevalence of oropharyngeal squamous cell carcinoma (OSCC) related to Human Papillomavirus (HPV) is rising in the whole world.

Objective To access the prevalence and temporal trend of HPV infection in oropharyngeal cancer by analyzing the expression of the p16 protein.

Methods We conducted a transversal study in a Brazilian reference oncology center. The sample consisted of 254 patients with OSCC. The analyzed period was from 2013 to 2017. All patients underwent p16 immunohistochemistry analysis.

Results The overall prevalence of HPV-related OSCC was of $31.9 \%$. During the analyzed period, we observed a trend of increasing rates of OSCC that marked positive for p16 immunohistochemistry. The annual prevalence of p16-positive cases was of $20.6 \%$ in $2013,23.9 \%$ in 2014, $33.3 \%$ in $2015,38.3 \%$ in 2016, and $34.2 \%$ in 2017 . Most of the patients were stage III and IV (84\%). Female patients (odds ratio $[O R]=2.43 ; 95 \%$ confidence interval $[\mathrm{Cl}]: 1.003-5.888 ; p=0.049)$ and younger patients $(\mathrm{OR}=2.919$; 95\%Cl: $1.682-5.067 ; p<0.005)$ were associated with a higher risk of HPV-related OSCC. Tobacco consumption had a proportional lower risk of HPV-related OSCC $(\mathrm{OR}=0.152 ; 95 \% \mathrm{Cl}$ : 0063-0.366; $p<0.005)$.

Conclusion We observed an increasing prevalence of HPV-related OSCC in a specialized cancer hospital in Brazil.
\end{abstract}

\section{Introduction}

Data from the Global Cancer Observatory (CLOBOCAN) from 2018 demonstrates that head and neck cancer are responsible for 1.454 .892 new cases per year, worldwide, and that the oropharynx represents one important subsite. ${ }^{1,2}$ Tobacco and

received

March 15, 2020

accepted

DOI https://doi.org/ 10.1055/s-0041-1730297. ISSN 1809-9777. alcohol consumption are traditional risk factors associated with this type of cancer; however, Human Papillomavirus (HPV) infection is consistently rising as the main risk factor for OSCC in Western and other developed countries, while tobacco and alcohol-related OSCC have decreased proportionally. ${ }^{3-6}$ 
In a European meta-analysis, the prevalence of tonsillar squamous cell carcinoma related to HPV was of $66 \%$, and in the United States, Jiron et al. observed that among nonsmokers, the prevalence of HPV-related OSSC was of $65.8 \%$, and in patients who never drank alcohol, the prevalence was of $71.4 \% .^{7,8}$ In Australia, an increasing temporal trend in HPV-related OSSC was observed in a study comparing 2 periods, from 1987 to 1995 and from 2006 to $2010 .^{9}$

In 2008, Fakhry et al. conducted one of the first multicenter clinical trials that confirmed a better prognosis for HPVassociated oropharyngeal cancer. ${ }^{10}$ Another important data published in 2012 by Ang et al. found that the 5-year overall survival in HPV-positive OSCC is > 80\%, while in HPV-negative OSCC, it is up to $40 \%$ in stage III and IV patients submitted to chemoradiation. ${ }^{11} \mathrm{~A}$ more recent paper also shows a better prognosis for HPV-related OSCC. ${ }^{12-15}$ This difference in prognoses explains why it is important to understand how HPV-associated OSCC is prevalent.

Few epidemiological data are available in Latin America and, particularly, in Brazil. Therefore, it is important to increase the knowledge of the prevalence of HPV-related OSCC and its temporal trend. A better understanding is vital to design public health policies, prevention plans, and to improve the treatment of these patients.

\section{Objective}

To evaluate the prevalence of oropharyngeal cancer related to HPV infection, and its temporal trend in a tertiary cancer hospital in Brazil.

\section{Methods}

We conducted a transversal study of all patients treated for OSCC in our institution, from 2013 to 2017. The inclusion criteria were confirmatory biopsy for OSCC and test for the immunohistochemical expression of the p16 protein. The present study was approved by the ethics board of the institution (approval number 2.995.435).

Clinical data such as age, gender, race, type of labor, marital status, staging, and region of Brazil were extracted from medical charts. Using the receiver operating characteristic curve (ROC curve) method, the age of 55 years old was selected as the cutoff to classify patients as younger ( $<55$ years old) and older ( $\geq 55$ years old).

The analysis of the $\mathrm{p} 16$ protein was performed using the CINtec P16 Histology standard kit (Roche, Basel, Switzerland) on BenchMarkGx and BenchMark Ultra equipment (Ventana Medical Systems, Oro Valley, AZ, USA).

The data was analyzed using IBM SPSS Statistics for Windows, version 20.0 (IBM Corp., Armonk, NY, USA). Initially, the data were tabulated considering the descriptive statistics (mean, standard deviation [SD], minimum, maximum, and quartiles) for quantitative data and frequency tables for the qualitative variables. The chi-squared test was used for qualitative variables. The statistical significance adopted was of $5 \%$ $(p<0.05)$.

\section{Results}

During the studied period, 363 patients were diagnosed with OSCC. Among them, 254 (69.9\%) were submitted to immunohistochemical analysis and, therefore, were included in the present study. We found 79 (31.9\%) p16-positive OSCC cases and 175 (68.1\%) p16-negative OSCC cases.

Most of our patients were male (88.6\%) and had advanced cancer staging (84\%). The mean age at diagnosis was 58.89 years old ( \pm 10.36 years old). - Table 1 describes the clinical and epidemiological characteristics of our series, and - Table 2 characterizes the location of the tumor.

The prevalence of HPV-related oropharyngeal cancer tested by p16 analysis over the years is shown in chart $\mathbf{1}$. Female gender was associated with a proportionally higher risk of HPV-related OSCC ( $\mathrm{OR}=2.43 ; 95 \% \mathrm{CI}$ : 1.003-5.888;

Table 1 Clinical and epidemiological characteristics and p16 results

\begin{tabular}{|c|c|c|c|c|}
\hline Variable & Subtype & Result & Positive/negative p16 result & Odds ratio (OR) \\
\hline \multirow[t]{2}{*}{ Gender } & Male & $225(88.6 \%)$ & $64(28.4 \%) / 161(71.6 \%)$ & \multirow{2}{*}{$\begin{array}{l}\mathrm{OR}=2.43 ; 95 \% \mathrm{Cl}: \\
1.003-5.888 ; p=0.049\end{array}$} \\
\hline & Female & $29(11.4 \%)$ & $15(78.9 \%) / 14(21.1 \%)$ & \\
\hline \multirow[t]{2}{*}{ Race } & Non-Caucasian & $62(25.5 \%)$ & $17(27.4 \%) / 45(72.6 \%)$ & \multirow{2}{*}{$\begin{array}{l}\mathrm{OR}=1.313 ; 95 \% \mathrm{Cl} ; \\
0.693-2.484 ; p=0.403\end{array}$} \\
\hline & Caucasian & $181(74.5 \%)$ & $60(33.1 \%) / 121(66.9 \%)$ & \\
\hline \multirow[t]{2}{*}{ Marital status } & Married & $128(51 \%)$ & $45(35.2 \%) / 83(64.8 \%)$ & \multirow{2}{*}{$\begin{array}{l}\mathrm{OR}=1.419 ; 95 \% \mathrm{Cl} \\
0.83-2.427 ; p=0.200\end{array}$} \\
\hline & $\begin{array}{l}\text { Single/Divorced/Widow } \\
\text { or Widower }\end{array}$ & $123(49 \%)$ & $34(27.6 \%) / 89(72.4 \%)$ & \\
\hline \multirow[t]{2}{*}{ Staging } & Initial (stage I/ II) & $40(16 \%)$ & $9(22.5 \%) / 31(77.5 \%)$ & \multirow{2}{*}{$\begin{array}{l}\mathrm{OR}=0.602 ; 95 \% \mathrm{Cl} ; \\
0.271-1.335 ; p=0.208\end{array}$} \\
\hline & Advanced (stage III/IV) & $209(84 \%)$ & $68(32.5 \%) / 141(67.5 \%)$ & \\
\hline \multirow[t]{2}{*}{ Age (years old) } & $<55$ & $91(35.8 \%)$ & $42(46.2 \%) / 49(53.8 \%)$ & \multirow{2}{*}{$\begin{array}{l}\mathrm{OR}=2.919 ; 95 \% \mathrm{Cl} \\
1.682-5.067 ; p<0.005\end{array}$} \\
\hline & $\geq 55$ & $163(64.2 \%)$ & $37(22.7 \%) / 126(77.3 \%)$ & \\
\hline \multirow[t]{2}{*}{ Tobacco } & Exposed & $204(88.31 \%)$ & $54(26.5 \%) / 150(73.5 \%)$ & \multirow{2}{*}{$\begin{array}{l}\mathrm{OR}=0.152 ; 95 \% \mathrm{Cl} \\
0063-0.366 ; p<0.005\end{array}$} \\
\hline & Notexposed & $27(11.69 \%)$ & $19(70.4 \%) / 8(29.6 \%)$ & \\
\hline
\end{tabular}


Table 2 Tumor topography in the oropharynx

\begin{tabular}{|l|l|}
\hline Tumor location & Frequency \\
\hline Base of the tongue & $47(18.5 \%)$ \\
\hline Tonsils & $102(40.2 \%)$ \\
\hline Uvula & $9(3.5 \%)$ \\
\hline Soft palate & $23(9.1 \%)$ \\
\hline Lateral and posterior wall & $15(5.9 \%)$ \\
\hline Vallecula & $7(2.8 \%)$ \\
\hline Undefined/overlapped & $51(20.1 \%)$ \\
\hline
\end{tabular}

$p=0.049$ ), and smokers or former smokers had a lower risk of HPV-related OSCC (OR $=0.152 ; 95 \% \mathrm{CI}$ : 0063-0.366; $p<0.005)$. Younger patients were associated with a higher risk of HPV-related OSCC (OR $=2.919 ; 95 \% \mathrm{CI}$ : 1.682-5.067; $p<0.005$ ) in our study.

The analysis did not demonstrate a difference in the association of p16-positive OSCC and race, location of the tumor, marital status and disease stage of the patient. Most of our patients were from the southeast or the midwest regions of Brazil (90.6\%), but patients of all regions of the country were included in the present study.

\section{Discussion}

Comparing published data before 2000 and after 2005, Mehanna et al. found an increase in the prevalence of HPV-related OSCC, from 40.5 to $72.2 \%$. The current prevalence of HPV-related OSCC in Europe is of $73.1 \%$ (95\%CI: 39.4-91.9,) and in the United States of America (USA), the prevalence is of $69.7 \%$ (95\%CI:46.8-85.7) according to this meta-analysis. ${ }^{16}$ Chatuverdi et al. observed an increase of 225\% in HPV-related OSCC cases between 1988 and 2004 in the USA. ${ }^{17}$ The proportion of HPV infection in patients with oropharyngeal cancer is lower in Asia, of $40.53 \%$ (95\%CI: 38.71-42.35). ${ }^{18}$ The Brazilian literature presents data with small series and, generally, the HPV status for OSCC is measured along with other head and neck subsites. A small series conducted by Petito et al. observed $25.6 \%$ of 43 cases, and López et al. found 4.4\% of HPV16 DNA-positive test in 91 patients with oropharyngeal cancer. ${ }^{19,20}$ A larger Brazilian study found out that among 346 OSCC patients, only $6.1 \%$ were positive for both p16 immunohistochemical and DNA analysis. ${ }^{21}$ Our results demonstrate an increasing temporal trend of HPV-related OSCC, which is in line with other countries. Recent papers from China and India, which are countries with socioeconomic characteristics similar to those of Brazil, also show HPV as an important risk factor for OSCC. In a Hong Kong study ranging from 1983 to 2014, there is an increasing rise of head and neck cancer subsites associated with HPV, and in India, Murthy et al. found that $20 \%$ of OSCC cases were p16-positive. ${ }^{22,23}$

Most of our cases were stage III and IV, which may be explained due to the deficiencies of the public health system, such as difficulty in accessing tertiary hospitals and delay in diagnosis and staging, but other factors, such as the educa- tional level of the patient, tumor biology, and HPV prevalence may also be involved. In our series, tonsillar cancer was responsible for the majority of cases, followed by undefined or overlapped oropharyngeal locations and the base of tongue, as shown in - Table 2 . These results are in line with other series. ${ }^{24,25}$ The high percentage of undefined or overlapped oropharyngeal locations may be partial explained by inaccurate data in medical records, but also by the high rates of advanced cancer stage, which makes difficult to define the epicenter of the tumor in the oropharynx by the examiner.

In patients who had p16-positive OSCC, 19 (26\%) were nonsmokers, and 54 (74\%) were smokers or former smokers; therefore, the minority of HPV-related OSCC cases were truly not exposed to tobacco. This result was also found by Ang et al. in a retrospective series among stage III and IV OSCC patients, in which $28 \%$ of the patients were nonsmokers, while $53.4 \%$ were former smokers, and $11.7 \%$ were smokers. ${ }^{26}$

We found a positive association between HPV-related OSCC and younger patients. Marur et al. and Leemans et al. also found this association. ${ }^{27,28}$ This may be explained due to the larger number of patients in this age group. In our series, female gender was associated with a higher risk of HPVrelated OSCC, which differs from the results found in other papers, such as a multicenter retrospective study conducted in the United Kingdom that found a higher proportion in males. ${ }^{29-31}$ Another study from the USA also demonstrates a higher incidence of HPV-related OSCC in males. ${ }^{17}$ Although the typical OSCC p16-positive patient is male, studies from India and Italy also demonstrate an association between female gender and HPV-related OSCC, like our series. We believe that this difference can be explained in part due to differences in smoking in women when compared with men. ${ }^{19,26}$

A possible bias associated to our data is that not all cases of oropharyngeal cancer were submitted to p16 analysis until 2017, when the American Joint Committee on Cancer (AJCC) incorporated the 16 status to oropharyngeal cancers staging. ${ }^{27}$ This issue could favor more tests in patients without tobacco and alcohol consumption in the early stages of the disease. However, this would rise the true HPV-positive proportion in the early stages of the disease, not invalidating the rising trend of positive cases. In fact, in the studied period, 363 patients were diagnosed with OSCC, but 109 (30.1\%) patients did not have their 16 status evaluated. Our institution is working on a new research including survival rates and other variables such as alcohol consumption, personal income, and sexual practices, in which we will recover all cases of oropharyngeal cancer from 2007 to 2017 and conduct p16 analysis in all cases. As far as the authors are aware, this is the first study to show this temporal trend in Brazil, and also the largest series. Errors related to the retrospective nature of this data can be overcome with a prospective multicentric data collection.

\section{Conclusion}

Our study shows that, in Brazil, we have a progressive increase in HPV-related OSCC cases, as in the rest of the 

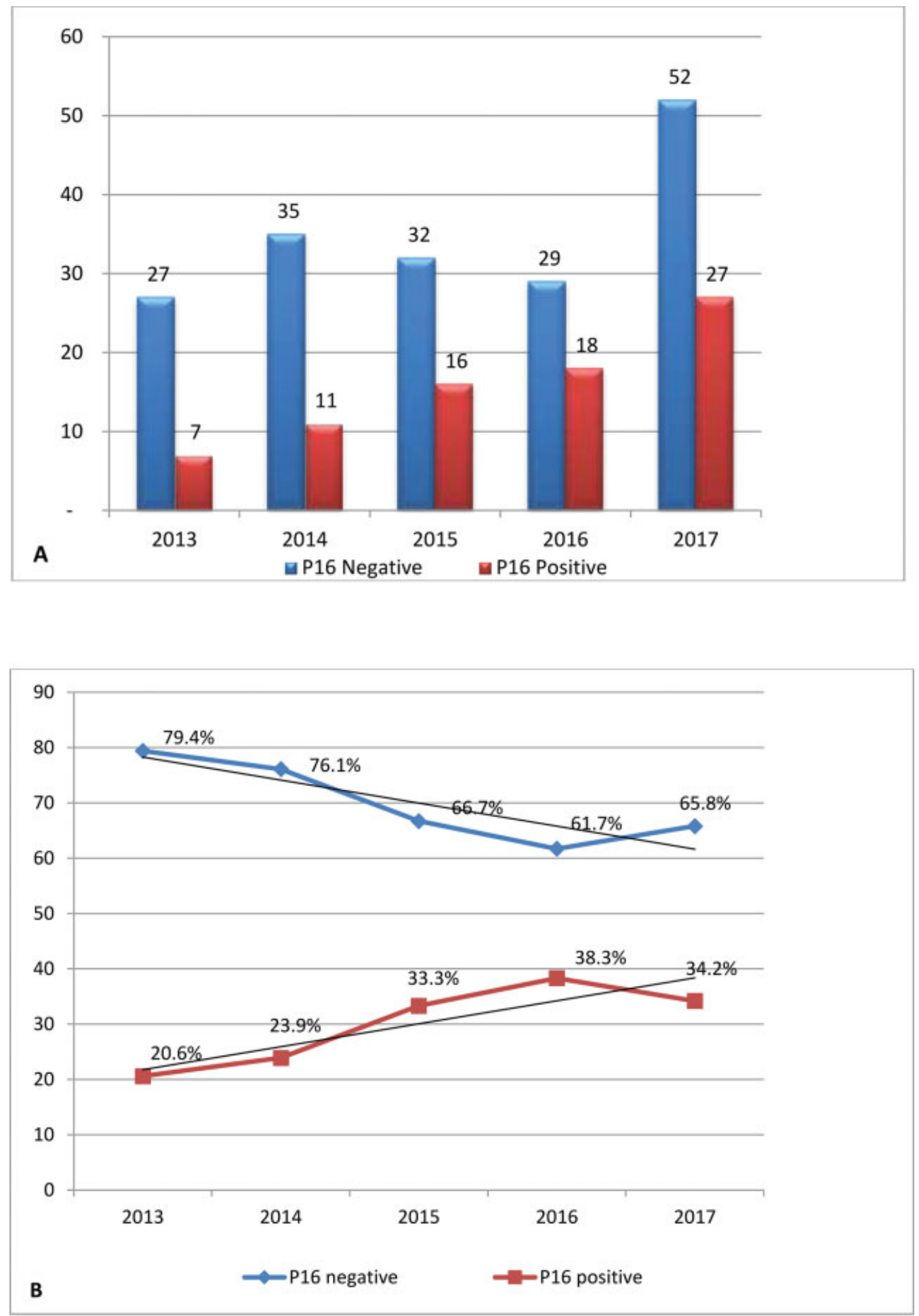

Chart 1 Annual trend of p16 protein. (A) Absolute data. (B) Temporal trend.

world. Female gender and younger age were associated with HPV-related OSCC, while tobacco consumption had a proportional lower risk of HPV-related OSCC.

\section{Conflict of Interests}

The authors have no conflict of interests to declare.

\section{References}

1 Bray F, Ferlay J, Soerjomataram I, Siegel RL, Torre LA, Jemal A. Global cancer statistics 2018: GLOBOCAN estimates of incidence and mortality worldwide for 36 cancers in 185 countries. CA Cancer J Clin 2018;68(06):394-424

2 Xu L, Dahlstrom KR, Lairson DR, Sturgis EM. Projected oropharyngeal carcinoma incidence among middle-aged US men. Head Neck 2019;41(09):3226-3234 
3 Vokes EE, Agrawal N, Seiwert TY. HPV-Associated Head and Neck Cancer. J Natl Cancer Inst 2015;107(12):djv344

4 Timbang MR, Sim MW, Bewley AF, Farwell DG, Mantravadi A, Moore MG. HPV-related oropharyngeal cancer: a review on burden of the disease and opportunities for prevention and early detection. Hum Vaccin Immunother 2019;15(7-8):1920-1928

5 Yakin M, Seo B, Hussaini H, Rich A, Hunter K. Human papillomavirus and oral and oropharyngeal carcinoma: the essentials. Aust Dent J 2019;64(01):11-18

6 Mena M, Frias-Gomez J, Taberna M, et al. Epidemiology of human papillomavirus-related oropharyngeal cancer in a classically lowburden region of southern Europe. Sci Rep 2020;10(01):13219

7 Abogunrin S, Di Tanna GL, Keeping S, Carroll S, Iheanacho I. Prevalence of human papillomavirus in head and neck cancers in European populations: a meta-analysis. BMC Cancer 2014; 14:968-981

8 Jiron J, Sethi S, Ali-Fehmi R, et al. Racial disparities in Human Papillomavirus (HPV) associated head and neck cancer. Am J Otolaryngol 2014;35(02):147-153

9 Hong A, Lee CS, Jones D, et al. Rising prevalence of human papillomavirus-related oropharyngeal cancer in Australia over the last 2 decades. Head Neck 2016;38(05):743-750

10 Fakhry C, Westra WH, Li S, et al. Improved survival of patients with human papillomavirus-positive head and neck squamous cell carcinoma in a prospective clinical trial. J Natl Cancer Inst 2008;100(04):261-269

11 Ang KK, Sturgis EM. Human papillomavirus as a marker of the natural history and response to therapy of head and neck squamous cell carcinoma. Semin Radiat Oncol 2012;22(02):128-142

12 Okami K. Clinical features and treatment strategy for HPV-related oropharyngeal cancer. Int J Clin Oncol 2016;21(05):827-835

13 De Felice F, Tombolini V, Valentini V, et al. Advances in the Management of HPV-Related Oropharyngeal Cancer. J Oncol 2019;2019:9173729

14 Bigelow EO, Seiwert TY, Fakhry C. Deintensification of treatment for human papillomavirus-related oropharyngeal cancer: Current state and future directions. Oral Oncol 2020;105:104652

15 Ringash J. Survivorship and Quality of Life in Head and Neck Cancer. J Clin Oncol 2015;33(29):3322-3327

16 Mehanna H, Beech T, Nicholson T, et al. Prevalence of human papillomavirus in oropharyngeal and nonoropharyngeal head and neck cancer-systematic review and meta-analysis of trends by time and region. Head Neck 2013;35(05):747-755

17 Chaturvedi AK, Engels EA, Pfeiffer RM, et al. Human papillomavirus and rising oropharyngeal cancer incidence in the United States. J Clin Oncol 2011;29(32):4294-4301
18 Shaikh MH, McMillan NAJ, Johnson NW. HPV-associated head and neck cancers in the Asia Pacific: A critical literature review \& meta-analysis. Cancer Epidemiol 2015;39(06):923-938

19 Petito G, Carneiro MA, Santos SH, et al. Human papillomavirus Q16 in oral cavity and oropharynx carcinomas in the central region of Brazil. Braz J Otorhinolaryngol 2017;83(01):38-44

20 López RV, Levi JE, Eluf-Neto J, et al. Human papillomavirus (HPV) 16 and the prognosis of head and neck cancer in a geographical region with a low prevalence of HPV infection. Cancer Causes Control 2014;25(04):461-471

21 Buexm LA, Soares-Lima SC, Brennan P, et al. Hpv impact on oropharyngeal cancer patients treated at the largest cancer center from Brazil. Cancer Lett 2020;477(01):70-75

22 Chan MH, Wang F, Mang WK, Tse LA. Sex Differences in Time Trends on Incidence Rates of Oropharyngeal and Oral Cavity Cancers in Hong Kong. Ann Otol Rhinol Laryngol 2018;127(12): 895-902

23 Murthy V, Swain M, Teni T, et al. Human papillomavirus/p16 positive head and neck cancer in India: Prevalence, clinical impact, and influence of tobacco use. Indian J Cancer 2016;53 (03):387-393

24 Cohan DM, Popat S, Kaplan SE, Rigual N, Loree T, Hicks WL Jr. Oropharyngeal cancer: current understanding and management. Curr Opin Otolaryngol Head Neck Surg 2009;17(02):88-94

25 Pytynia KB, Dahlstrom KR, Sturgis EM. Epidemiology of HPVassociated oropharyngeal cancer. Oral Oncol 2014;50(05): 380-386

26 Ang KK, Harris J, Wheeler R, et al. Human papillomavirus and survival of patients with oropharyngeal cancer. N Engl J Med 2010;363(01):24-35

27 Marur S, D'Souza G, Westra WH, Forastiere AA. HPV-associated head and neck cancer: a virus-related cancer epidemic. Lancet Oncol 2010;11(08):781-789

28 Leemans CR, Braakhuis BJM, Brakenhoff RH. The molecular biology of head and neck cancer. Nat Rev Cancer 2011;11(01):9-22

29 Schache AG, Powell NG, Cuschieri KS, et al. HPV-Related Oropharynx Cancer in the United Kingdom: An Evolution in the Understanding of Disease Etiology. Cancer Res 2016;76(22):6598-6606

30 Boscolo-Rizzo P, Zorzi M, Del Mistro A, et al; AIRTUM Working Group. The evolution of the epidemiological landscape of head and neck cancer in Italy: Is there evidence for an increase in the incidence of potentially HPV-related carcinomas? PLoS One 2018; 13(02):e0192621

31 Amin MB, Edge S, Greene F, Byrd DR, Brookland RK, Washington MK, et al. AJCC Cancer Staging Manual. 8th ed. New York: Springer; 2017 